UCRL-TR-203351

\title{
Sampling ENDL Watt Fission Spectra
}

\author{
by \\ Dermott E. Cullen \\ University of California \\ Lawrence Livermore National Laboratory \\ P.O. Box 808 \\ L-159 \\ Livermore, CA 94550
}

tele: $510-423-7359$

E. Mail: cullen1@llnl.gov

website: http://www.llnl.gov/cullen1

April 1, 2004

U.S. Department of Energy

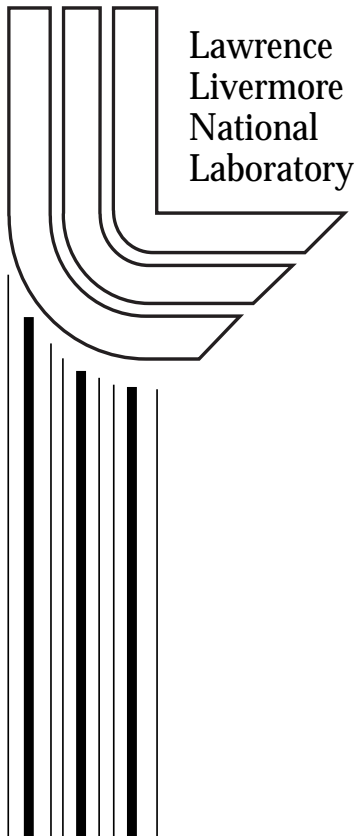

Approved for public release; further dissemination unlimited. 


\section{DISCLAIMER}

This document was prepared as an account of work sponsored by an agency of the United States Government. Neither the United States Government nor the University of California nor any of their employees, makes any warranty, express or implied, or assumes any legal liability or responsibility for the accuracy, completeness, or usefulness of any information, apparatus, product, or process disclosed, or represents that its use would not infringe privately owned rights. Reference herein to any specific commercial product, process, or service by trade name, trademark, manufacturer, or otherwise, does not necessarily constitute or imply its endorsement, recommendation, or favoring by the United States Government or the University of California. The views and opinions of authors expressed herein do not necessarily state or reflect those of the United States Government or the University of California, and shall not be used for advertising or product endorsement purposes.

Work performed under the auspices of the U. S. Department of Energy by the University of California Lawrence Livermore National Laboratory under Contract W-7405-Eng-48.

This report has been reproduced directly from the best available copy.

Available to DOE and DOE contractors from the

Office of Scientific and Technical Information

P.O. Box 62, Oak Ridge, TN 37831

Prices available from (423) 576-8401

http://apollo.osti.gov/bridge/

Available to the public from the National Technical Information Service

U.S. Department of Commerce 5285 Port Royal Rd., Springfield, VA 22161 http://www.ntis.gov/

OR

Lawrence Livermore National Laboratory Technical Information Department's Digital Library http://www.llnl.gov/tid/Library.html 


\title{
Sampling ENDL Watt Fission Spectra
}

UCRL-TR-203251

\author{
by \\ Dermott E. Cullen \\ University of California \\ Lawrence Livermore National Laboratory \\ P.O. Box 808 \\ L-159 \\ Livermore, CA 94550
}

tele: $510-423-7359$

E. Mail: cullen1@llnl.gov

website: http://www.llnl.gov/cullen1

April 1, 2004

\section{Introduction}

All of the fission spectra in the Evaluated Nuclear Data Library, ENDL [1], are defined by a simple analytical function: a Watt spectrum [2],

$\mathrm{W}\left(\mathrm{a}, \mathrm{b}, \mathrm{E}^{\prime}\right)=\mathrm{C}^{*} \mathrm{Exp}\left[-\mathrm{a}^{*} \mathrm{E}^{\prime}\right]^{*} \operatorname{Sinh}\left[\left(\mathrm{b}^{*} \mathrm{E}^{\prime}\right)^{1 / 2}\right]$

Where the normalization, $\mathrm{C}$, is given by,

$\mathrm{C} \quad=[\pi \mathrm{b} / 4 \mathrm{a}]^{1 / 2} \operatorname{Exp}[\mathrm{b} / 4 \mathrm{a}] / \mathrm{a}$

The coefficients a and $\mathbf{b}$ vary from one isotope to another and also vary weakly with the incident neutron energy. Here $\mathbf{E}$ ' is the secondary energy, i.e., the energy at which the fission neutrons are emitted. In ENDL energy units of $\mathrm{MeV}$ for incident neutron energies between 0 and $20 \mathrm{MeV}$, in all cases $\mathbf{b}$ is very close to 1.0, and a varies over a rather small range near 1.0 .

Currently there are 38 fissionable isotopes in ENDL. For each of these isotopes I have parameterized $\mathbf{a}$ as a simple function of the incident neutron energy, and I treat $\mathbf{b}$ as always equal to unity. The values of these parameters are available to TART users as part of the TART CD package [3]. This parameterization coupled with the general Watt sampling method described below results in a very fast and accurate method of sampling all of the fission spectra in ENDL. In all cases I select the fissioning isotope, define a based on isotope and incident neutron energy, and then use the below described method to sample the energy E' of a neutron emitted due to fission. 


\section{Example Watt Spectra}

Below is shown the fission spectra for $\mathrm{U}^{235}$ at very low and high energies. Over this energy range a varies over a narrow range from 0.92 at low energy to 0.70 at high energy. From this figure we can see the square root of E' variation at low energy and strongly decreasing exponentially variation at high energy. We can also see the hardening of the spectrum with incident neutron energy, where the average secondary energy E' of neutrons emitted due to fission for low energies incident neutrons is quite a bit lower than that due to fission for high energy incident neutrons. Finally note the extreme range of the spectra which is this case varies by over 6 orders of magnitude, which makes accurate sampling difficult unless many samples are used.

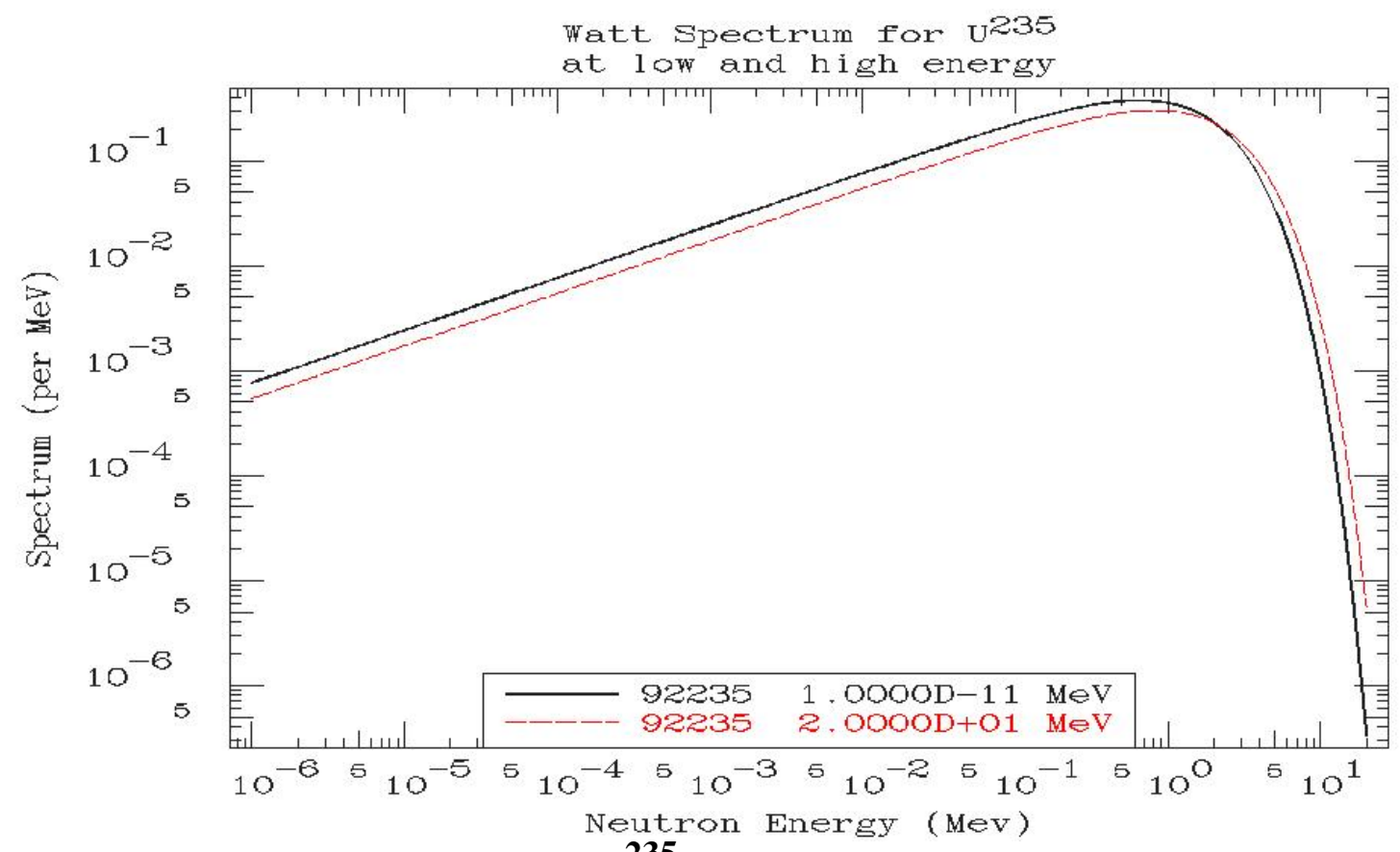

Fig. 1: $\mathrm{U}^{235}$ Fission Spectra 


\section{Sampling a Watt Spectrum}

The following sampling method is from Los Alamos’ Monte Carlo sampler [4], identified as R12, and attributed to Mal Kalos; for details see ref. [4],

Define $\mathrm{K}, \mathrm{L}$ and $\mathrm{M}$ once,

$\mathrm{K}=1+(\mathrm{b} / 8 \mathrm{a})$

$\mathrm{L} \quad=\left[\mathrm{K}+\left(\mathrm{K}^{2}-1\right)^{1 / 2}\right] / \mathrm{a}$

$\mathrm{M} \quad=\mathrm{a}^{*} \mathrm{~L}-1$

Define, $\mathrm{x}$ and $\mathrm{y}$, where $\mathrm{R} 1$ and $\mathrm{R} 2$ are random numbers,

$\mathrm{x} \quad=-\log [\mathrm{R} 1]$

$\mathrm{y} \quad=-\log [\mathrm{R} 2]$

Reject if $[y-M(x+1)]^{2}>b * L * x$, and define $x$ and $y$ again.

Otherwise accept and define the secondary energy,

$\mathrm{E}^{\prime} \quad=\mathrm{L}^{*} \mathrm{X}$

This is a very simple and very fast sampling method, e.g., on my PC it takes about 0.3 $\mu$ sec per sample, or about 200 million samples per minute.

\section{Limits of the Watt Spectrum}

For small E',

$\operatorname{Sinh}(x)=x+x^{3} / 3 !+x^{5} / 5 !+\ldots \ldots$.

So that for small $\mathrm{E}^{\prime}$ the spectrum approaches

$$
\begin{aligned}
\mathrm{W}\left(\mathrm{a}, \mathrm{b}, \mathrm{E}^{\prime}\right) & =\mathrm{C}^{*} \operatorname{Exp}\left[-\mathrm{a}^{*} \mathrm{E}^{\prime}\right]\left[\left(\mathrm{b}^{*} \mathrm{E}^{\prime}\right)^{1 / 2}+\ldots \ldots \ldots\right. \\
& =[\pi \mathrm{b} / 4 \mathrm{a}]^{1 / 2} \operatorname{Exp}[\mathrm{b} / 4 \mathrm{a}] / \mathrm{a} \operatorname{Exp}\left[-\mathrm{a}^{*} \mathrm{E}^{\prime}\right]\left[\mathrm{b}^{*} \mathrm{E}^{\prime}\right]^{1 / 2} ; \operatorname{Exp}\left[-\mathrm{a}^{*} \mathrm{E}^{\prime}\right] \sim 1 \\
& =[\mathrm{b} / 4 \mathrm{a}]^{*} \operatorname{Exp}[\mathrm{b} / 4 \mathrm{a}]\left[2 \pi^{*} \mathrm{E}^{\prime} / \mathrm{a}\right]^{1 / 2}
\end{aligned}
$$

So that we have a square root of $E^{\prime}$ dependence for small $E^{\prime}$,

$\mathrm{W}\left(\mathrm{a}, \mathrm{b}, \mathrm{E}^{\prime}\right)=\mathrm{A}^{*} \mathrm{E}^{, 1 / 2}$

For large E',

$\operatorname{Sinh}(\mathrm{x})=\operatorname{Exp}[\mathrm{x}] / 2$

So that for large $\mathrm{E}$ ' the spectrum approaches,

$\mathrm{W}\left(\mathrm{a}, \mathrm{b}, \mathrm{E}^{\prime}\right)=\mathrm{C}^{*} \operatorname{Ex}\left[-\mathrm{a}^{*} \mathrm{E}^{\prime}\right] \operatorname{Exp}\left[\left(\mathrm{b}^{*} \mathrm{E}^{\prime}\right)^{1 / 2}\right] / 2=\mathrm{C}^{*} \operatorname{Exp}\left[-\mathrm{a}^{*} \mathrm{E}^{\prime}+\left(\mathrm{b}^{*} \mathrm{E}\right)^{1 / 2}\right] / 2$

Note that $-a^{*} E^{\prime}$ defines a decreasing exponential, whereas $+\left(b^{*} E\right)^{1 / 2}$ defines an

increasing exponential. We can see that for a and $\mathrm{b}$ near 1 . the $+(\mathrm{b} * \mathrm{E})^{1 / 2}$ term will dominate below about $1 \mathrm{MeV}$ and the $-\mathrm{a}^{*} \mathrm{E}$ ' term above about $1 \mathrm{MeV}$. In the high energy limit of $20 \mathrm{MeV}$ that we are interested in $-\mathrm{a}^{*} \mathrm{E}$ ' dominates,

$\mathrm{W}\left(\mathrm{a}, \mathrm{b}, \mathrm{E}^{\prime}\right)=\mathrm{C}^{*} \operatorname{Exp}\left[-\mathrm{a}^{*} \mathrm{E}^{\prime}\left\{1-\left(\mathrm{b} / \mathrm{a}^{2} \mathrm{E}^{\prime}\right)^{1 / 2}\right\}\right] / 2 \rightarrow \mathrm{C}^{*} \operatorname{Exp}\left[-\mathrm{a}^{*} \mathrm{E}^{\prime}\right]$

and the spectrum is exponentially decreasing for large E'. 


\section{Sampled Results}

The following figures illustrate the comparison between an analytic Watt spectrum and sampled results for a typical Watt spectrum with $\mathbf{a}=0.7, \mathbf{b}=1.0$, similar to the above spectra for $\mathrm{U}^{235}$ with neutrons incident at $20 \mathrm{MeV}$. For these figures I used $10^{10}$ samples, which because of the speed of the sampling took less than one hour on a PC. From the first figure we can see very few samples at very low energies, as indicated by the increasing sampling "noise" below about $1 \mathrm{keV}$. From the second figure we can see excellent convergence over the higher energy range $10 \mathrm{keV}$ and $20 \mathrm{MeV}$ with agreement to within $1 \%$ over this entire energy range.

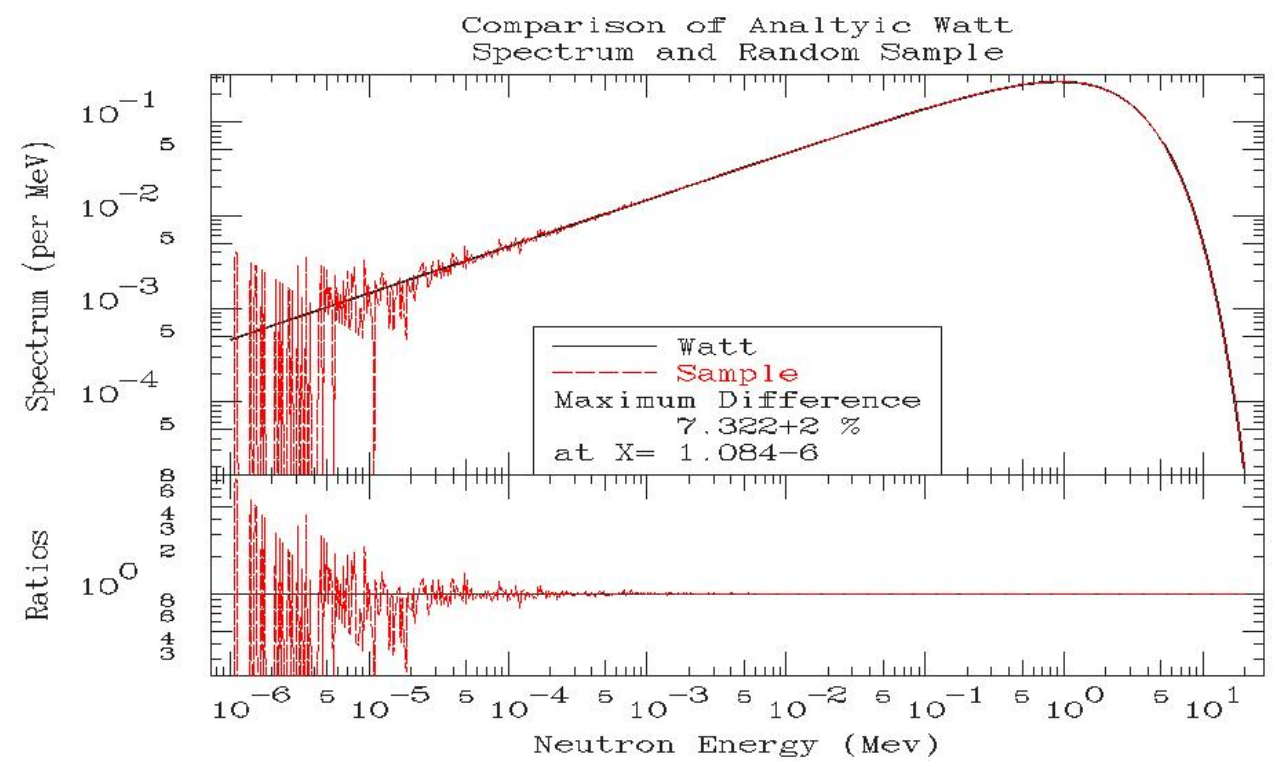

Fig. 2: Comparison of Analytic and Sampled Watt

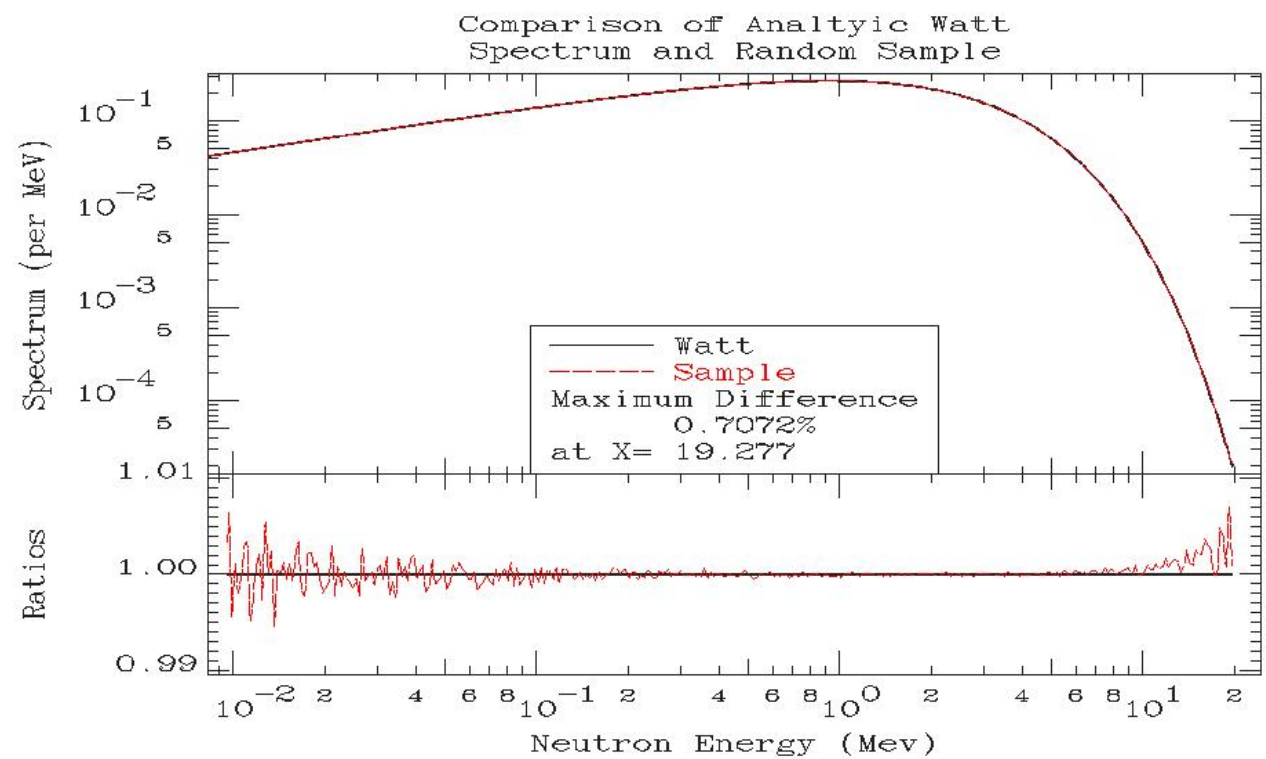

Fig. 3:Detail of Comparison of Analytic and Sampled Watt 


\section{What's in ENDL?}

The fission spectra included in the ENDL library are based on the Watt spectrum described above. However, in ENDL the WATT equation is not included; instead the data is represented as a table of (energy, spectrum) pairs with linear interpolation between tabulated points. For some reason this table only extends from $20 \mathrm{keV}$ upward in energy, as shown below.

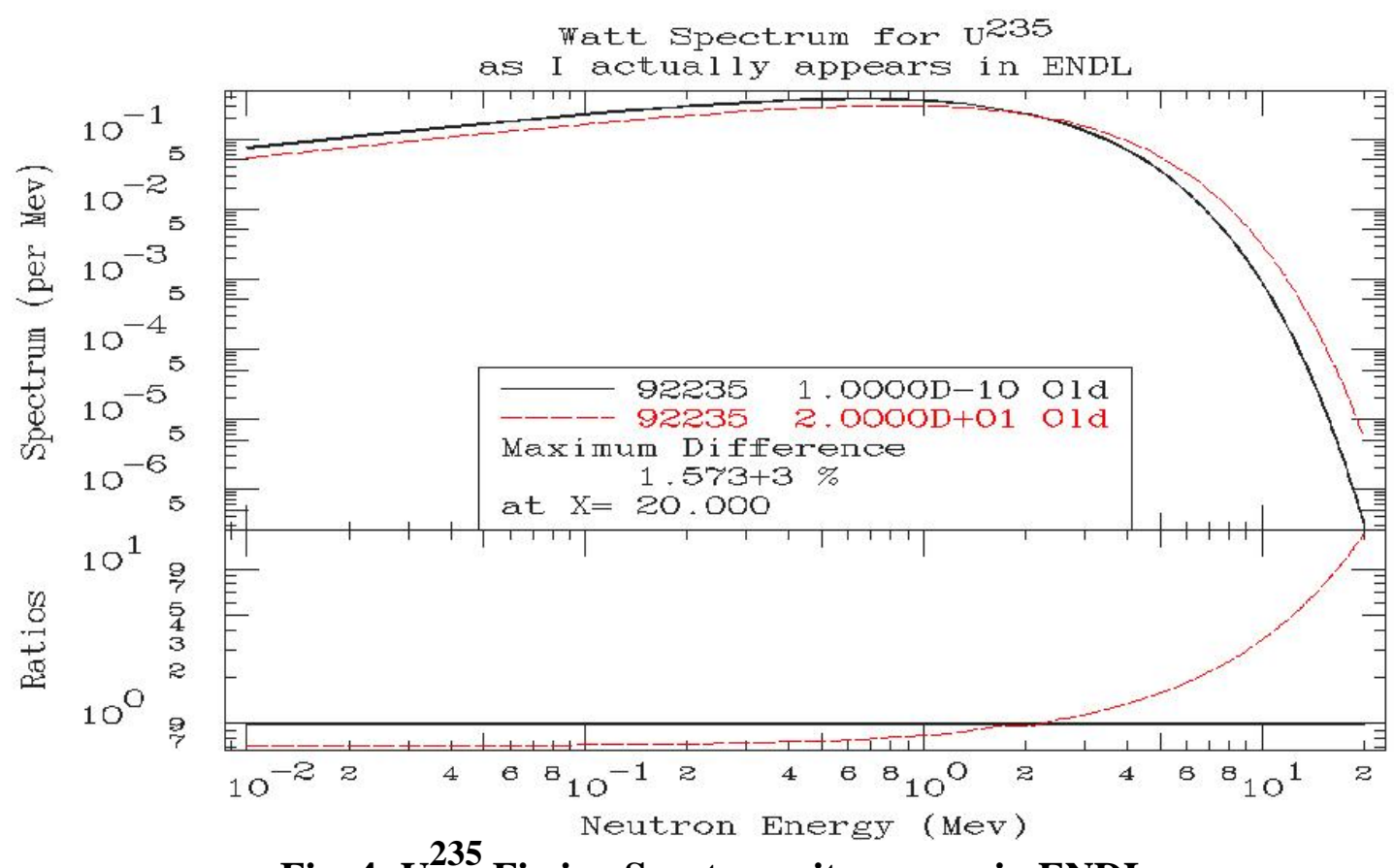

Fig. 4: $\mathrm{U}^{235}$ Fission Spectra as it appears in ENDL

This leads to some "strange" looking results when this data is used in applications, as shown in the below comparison of the neutron production spectra using TART, which sampled the analytical Watt spectrum directly, and MERCURY, which used the tabulated spectra from ENDL. Here TART sampled the analytical Watt spectra and we can see the spectrum extending down to low energy in the eV range. In contrast MERCURY sampled the tabulated fission spectra in ENDL. Note, the drop in the MERCURY spectra by about an order of magnitude at $10 \mathrm{keV}$; this is due to the ENDL fission spectra being cutoff at this point in energy. 


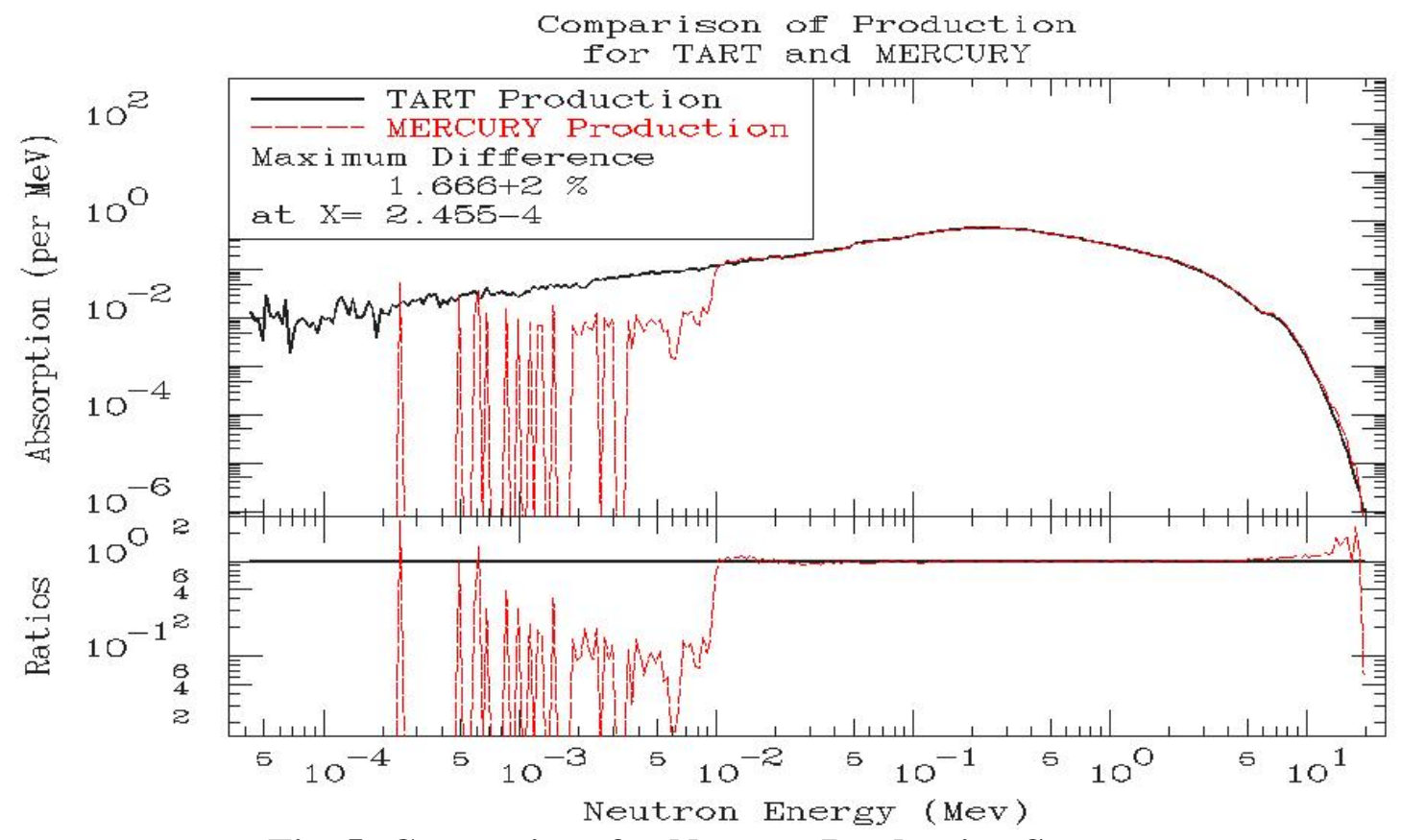

Fig. 5: Comparison for Neutron Production Spectra

The neutron data used by TART was originally based on ENDL, but more recently it is based on a combination of ENDF/B-VI plus some ENDL data. The ENDL fission spectra were included in this data base, even though TART no longer uses them; TART samples the analytical Watt spectrum directly. For the convenience of those codes that can use the TART data and do sampled the included fission spectra (e.g., COG and MERCURY) I recently extended the tabulated fission spectra from $10 \mathrm{eV}$ down to $1 \mathrm{eV}$, and added more detail to improve the accuracy of this tabulated data. This should eliminate the "strange" looking results as seen in the above results. As a more general improvement than merely the TART data, recently the ENDL fission spectra were also extended downward in energy in the ENDL library [5]. 


\section{References}

[1] The LLL Evaluated Nuclear Data Library (ENDL): Evaluation Techniques, Reaction Index, and Description of Individual Evaluations, UCRL-50400, Vol. 15, Part A, by R. J. Howerton, et. al, Sept. 1975, Lawrence Livermore National Laboratory

[2] Private Communication, 1996, Roger M. White; Roger and Bob Howerton are the people who about a decade ago updated the ENDL fission spectra to all be Watt spectra.

[3] TART 2002: A Coupled Neutron-Photon 3-D, Combinatorial Geometry, Time Dependent Monte Carlo Transport Code, Report: UCRL-ID-126455, Rev. 4, Code Release: UCRL-CODE-2003-043, by D.E. Cullen, July 2003, Lawrence Livermore National Laboratory. TART 2004, to be published. TART 2002 report is available on-line at http://www.llnl.gov/cullen1/mc.htm

[4] A Third Monte Carlo Sampler, LA-9721-MS, March 1983, by C.J. Everett and E.D. Cashwell, Los Alamos National Laboratory

[5] Private Communication, 2004, Roger M. White; Roger recently updated the ENDL fission spectra to extend them down from $10 \mathrm{keV}$ to $10 \mathrm{eV}$. 
University of California

Lawrence Livermore National Laboratory

Technical Information Department

Livermore, CA 94551

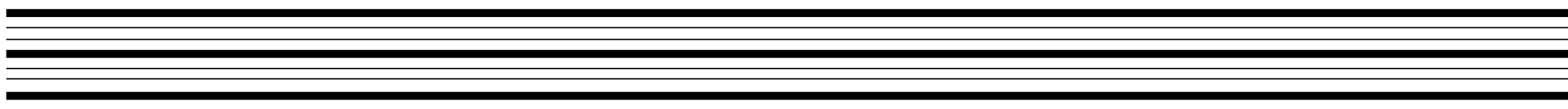

